\title{
Poética del belarte en la nota a pie: el texto bifurcado de Macedonio Fernández
}

\author{
Eva Ariza Trinidad ${ }^{1}$
}

Resumen. La nota a pie de página en la poética de Macedonio Fernández, el belarte que explica y ejercita en sus textos, se configura como un lugar privilegiado para la instancia textual del autor, donde esta reflexiona y dialoga con el lector. Varias veces, Macedonio Fernández experimenta con las notas para evidenciar su carácter bifurcador, para cuestionar su naturaleza liminal, y desarrollar funciones insólitas: cambiar el estatus no ficcional de los textos, determinar metalepsis ficcionales y restablecer la cohesión textual del belarte fragmentario y sin asunto del autor.

Palabras clave: Macedonio Fernández; paratextos; belarte; Estética de la Recepción; Teoría de la Literatura.

\section{[en] The poetics of 'Belarte' in footnotes: the forked text in Macedonio Fernández}

\begin{abstract}
Footnotes in Macedonio Fernández's poetics, the concept of belarte he introduces and develops in his texts, form a privileged space for the author as a textual agent to ponder and interact with the reader. On several occasions, Macedonio Fernández experiments with footnotes in order to reveal their forking character, question their liminal nature and perform unusual functions: change the texts' non-fictional status, determine fictional metalepses and re-establish the textual cohesion of the author's fragmentary, topicless belarte.

Keywords: Macedonio Fernández; paratexts; belarte; Reception Theory; Literary Theory.
\end{abstract}

Cómo citar: Ariza Trinidad, E. (2021) Poética del belarte en la nota a pie: el texto bifurcado de Macedonio Fernández, en Anales de Literatua Hispanoamericana 50, 307-317.

No es difícil imaginar las secretas afinidades de Macedonio Fernández con las disciplinas estéticas susceptibles de alumbrar obras de arte compuestas fragmentariamente. Él sentía predilección por la psicología, la metafísica, la biología, la música (concretamente, la guitarra), el problema del Arte y la Estética de la Novela (Gómez de la Serna, 2001: 8). Las facetas de tantos hombres en solo uno también sustentan, imaginariamente, la afinidad secreta de su obra con el arte fragmentario y con la perspectiva de que la paratextualidad - en cierto modo, una forma expansiva y fragmentada de los textos - puede usarse como un recurso sustancial de este tipo de arte.

Varios estudios significativos de la narrativa hispanoamericana del siglo pasado, en los cuales se analiza la obra de Macedonio Fernández, enfatizan el carácter vanguardista de la narrativa del autor (Bustos, 1996: 28-29; Camblong, 2006: 45-63; Niemeyer, 1994: 243-246; Sosnowsky, 1987: 146-147; et. al.) y lo fundamentan en algunos rasgos que anticipan los del nuevo arte: a) la naturaleza fragmentaria de las narraciones (Becco, 1973: 126; Echavarren, 1979: 97; Jitrik, 1973: 76; Prieto, 2010: 17-35; et. al.), derivada de la despreocupación de Macedonio Fernández por la coherencia y cohesión del texto, dada "su empecinada convicción acerca de la libertad de pensamiento en las búsquedas imaginarias" (Camblong, 2007:147); b) el carácter liminal de sus escritos, donde se mezclan pasajes literarios y filosóficos (Lindstrom, 1985: 152) y la representación de lo real y lo ficcional se confunde (Niemeyer, 1994: 252); c) el carácter metateórico de su narrativa, pues los textos del autor manifiestan teorías implícitas de la Estética de la Recepción a través de sujetos-personajes que son enunciadores y enunciatarios, con los cuales se muestra la comunicación literaria como acto incompleto y la adhesión de un lector idealizado a la estética macedoniana (Luque, 2017;

\footnotetext{
${ }^{1}$ Universidad Complutense de Madrid. España.

E-mail: evariza@ucm.es
} 
Borinski, 1972: 43-45; Jitrik, 1973: 83-84; Lindstrom, 1985: 158-159; et. al.); y d) el humorismo, rasgo omnipresente en los textos del autor (Camblong, 2006: 85-110; Cívico-Lyons, 2017; Echavarren, 1979: 97; García, 2000: 39-43, 74-76; et. al.).

Asimismo, otro de los temas más tratados en la teoría y crítica sobre Macedonio Fernández es la proyección se su obra en escritores posteriores, sobre todo, en la narrativa de Jorge Luis Borges (Attala, 2014; Camblong, 2006: 111-163; Díaz, 1990: 498-499; Mattalía, 1992; et. al.). No obstante, cabe destacar la sorprendente ausencia de estudios específicos sobre el uso de la paratextualidad en las narrativas de ambos, legado indudable de Macedonio Fernández. Habitualmente, se alude al carácter paratextual de los textos del autor y al particular uso que hace de las notas a pie de página, prólogos, epílogos (Bustos, 1996: 48; Luque, 2017: 82; Niemeyer, 1994: 446; Orquera, 1994: 56-58; et. al.), también en la configuración de la estructura de los minicuentos que inserta Macedonio Fernández en sus textos (González, 1998: 605). De todos los paratextos articulados en la narrativa macedoniana, se alude principalmente a los prólogos, cuya función estructuradora se evidencia en Museo de la novela de la Eterna (Primera novela buena). Estos se han analizado desde un punto de vista filosófico en "El mundo en estado de prólogo", el capítulo que le dedica Horacio González a este paratexto (González, 1995: 95-144), sin embargo, aún no se han desarrollado análisis específicos de las funciones y contribuciones a las estética macedoniana de este y otros paratextos, como las citas, los epílogos y las notas a pie de página. Acaso Ana Camblong aporta la definición más cercana al propósito de este estudio: "digresión: la nota al pie discurre caminando por los bordes del texto y de la temática en una táctica reiterada que potencia la simultaneidad de abordajes y la polifonía a la manera de una conversación" (Camblong, 2007: 169).

Los paratextos, textos que se desarrollan a las orillas de otros, habitualmente para matizarlos, explicitarlos, comentarlos o ampliarlos, manifiestan cierto carácter dialógico con el texto que circundan y con el lector. De los diferentes paratextos (títulos, dedicatorias, intertítulos, prefacios...), las notas ${ }^{2}$ — estén o no a pie de página - tienen un carácter dialógico más pronunciado, como explica Genette al tratar las formas de relación que establecen con el texto: "Con la nota, sin duda tocamos una, o mejor dicho muchas, de las fronteras, o ausencia de fronteras que rodean el campo, eminentemente transicional, del paratexto. [...] [Las notas] están tan estrechamente relacionadas con tal o cual detalle de tal texto que no tienen, por así decir, ninguna significación autónoma" (Genette, 2001: 272).

El sentido de la nota a pie de página depende directamente del texto, un rasgo derivado del diálogo irrevocable que mantiene con él; un rasgo, asimismo, que Macedonio Fernández explora y modifica de forma creativa y en el que se fundamenta parcialmente su poética, a la cual denomina "belarte". Probablemente, Macedonio Fernández usa este término con el propósito desautomatizador que se intuye en toda su obra, para que el lector asuma el significado particular que él le confiere, sin el velo del significado normativo del concepto asociado a este. Así, con "belarte" se refiere al único arte que él concibe ${ }^{3}$ : emoción y no sensación - ya que esta suele orientarse al efectismo, entendido como "efecto agradable"-, técnica creadora indirecta, artificio que suscita un efecto de vida y jamás recrea un argumento:

Belartes llamo, únicamente, a las técnicas indirectas (no directas: copia o imitación) de suscitación de estados psicológicos en otras personas, que no sean ni los que siente el autor ni los que aparentan sentir los personajes en cada momento. Los "asuntos" son extraartísticos, no tienen calidad de arte, y deben ser meros pretextos para hacer operar la técnica, por lo que extraña en Porto-Riche, y más aún en Goethe, la banalidad del pueril catálogo de asuntos. Fuera de la técnica no hay arte; la invención del "asunto" es un juego inocente frente a la riqueza de tramas y temas cotidianos. La vida es la todo-posibilidad; no hay carácter, acto ni suceso material que no sea tan posible como cualquier otro, y la socorrida "congruencia" de carácter,

\footnotetext{
${ }^{2}$ Gérard Genette define la nota al pie de la siguiente manera: "Una nota es un enunciado de extensión variable (una palabra es suficiente) relativo a un segmento más o menos determinado del texto, y dispuesto ya sea junto a ese segmento o en referencia a él" (Genette, 2001: 272).

${ }^{3}$ En Teorías, Macedonio define así "belarte": "Belarte debe llamarse al Arte, para excluir netamente la sensorialidad, cuyo oficio y cultivo debe llamarse Culinaria. Yo propondría como mejor nombre del Arte el de Autorística” (Fernández, 1997: 235). Por otra parte, en Diccionario de la novela de Macedonio Fernández se resumen lo rasgos del belarte de la siguiente manera:

1. Suma de teorías estéticas de Macedonio Fernández.

2. Macedonio opone Arte, entendido como Invención, a la concepción mimética de la tradición realista [...].

Con el término Belarte, Macedonio designa las obras de invención pura [...], que se proponen generar una conmoción de la seguridad intelectual y ontológica del lector a través de un plan consciente de técnicas indirectas, y que se restringen a la exclusividad de su propio material $[\ldots]$.

Toda obra de arte entendida como invención supone el autocuestionamiento y la indagación conceptual, incluso de parte del artista [...] (Piglia, 2000: 18).
} 
"verosimilitud" de acto o suceso, desesperado argumento para defender el realismo (que no es arte porque no es mera técnica, sino información que incumbe a la ciencia), son cosas que nunca existieron en la vida y menos pudieron percibirse a través de lo escrito (Fernández, 1997: 236).

La necesaria ausencia de un asunto en el belarte configura una creación fragmentaria, discontinua e interrumpida, donde el espacio apenas se representa y la sucesión temporal se desvanece "hasta convertir las ideas en objetos concretos que proyectan su inasible consistencia en el vacío" (Salvador, 2003: 16).

La naturaleza digresiva de los paratextos, especialmente la de las notas a pie de página, y el carácter fragmentario son rasgos afines a los textos de Macedonio Fernández, quien consolida la estética de las digresiones - afín al no-asunto-, en algunas de las obras más significativas que se publicaron cuando vivía (No todo es vigilia la de los ojos abiertos - 1928- Papeles de Recienvenido - 1929- y Continuación de la Nada - mitad inconfundiblemente segunda de la obra anterior, publicada en 1944-), y tras su muerte (Museo de la Novela de la Eterna -1967-). En ellas, se observa cierto gusto por explorar las posibilidades de los rasgos de los paratextos afines al belarte; y Macedonio Fernández tanteó primero las de las notas a pie de página, probablemente por su notable carácter dialógico y digresivo.

Para analizar cualquier desviación de la norma, se precisa delimitar lo normativo; y en ello deben contemplarse las desviaciones normativizadas, aquellas que algunos autores imitaron de otros - el proceso por el cual la desviación se transforma en recurso- . Gérard Genette establece una clasificación de las notas en Umbrales, que conviene recordar para mostrar el uso específico, belartístico, de Macedonio Fernández: las notas originales y las ficcionales. Las primeras son aquellas que el autor utiliza habitualmente en los textos discursivos con un propósito puramente paratextual y cuyas funciones son: complementar el texto con explicaciones de términos utilizados, traducciones de citas en la lengua original (diferente a la del texto), información de las fuentes utilizadas y de otras fuentes de interés...; comentar el texto para aclarar términos imprecisos o complejos, irrelevantes para algunos lectores, pero significativos para los expertos en la materia tratada; y la función digresiva, con la cual se evidencia que la nota es un segundo nivel del discurso, que dialoga con el primero y, en cierto modo, se integra en él:

Pues la principal virtud de la nota es que permite administrar en el discurso efectos locales de matiz, de sordina, o, como se dice también en música, de registro, que contribuyen a reducir su famosa (y a veces molesta), linealidad [...].

Pero se ve bien que esta justificación de la nota autoral (original) sea al mismo tiempo, en cierta medida, cuestionamiento de su carácter paratextual. La nota original es una bifurcación momentánea del texto, y en ese sentido le pertenece tanto como un simple paréntesis. Estamos aquí en una franja indecisa entre el texto y paratexto (Genette, 2001: 280).

El segundo tipo de notas que define Genette, las ficcionales, se caracteriza por que su emisor es una entidad ficcional ${ }^{4}$ (se trata de un emisor representado): "Recordaré que no llamo de este modo a las notas auténticas serias que pueden acompañar una obra de ficción, sino las del texto, ficcional o no, cuyo destinador es en algún sentido ficcional: denegativo, ficticio o apócrifo" (Genette, 2001: 291). Genette también indica que una de las notas ficcionales más habituales es la seudoeditorial, aquella en que la entidad enunciativa se hace pasar por el editor del texto:

La nota autoral denegativa, o seudoeditorial, es un género completamente clásico y particularmente bien ilustrado [...]. Como en los prefacios del mismo tipo, el autor se presenta aquí como editor, responsable de todos los detalles del control y el establecimiento del texto, que pretenden haber tomado a cargo o recibido (Genette, 2001: 291).

Este tipo de notas también recibe el nombre de "autoral denegativa" porque el autor oculta su identidad y adopta otra (por ejemplo, la de editor, en las notas seudoeditoriales). De este modo, puede considerarse otro tipo de nota autoral denegativa aquella en que el autor revela su función autoral; es decir, cuando escribe el "autor", una máscara del autor que se conforma al explicitar cierta autoconciencia de la autoría del texto. Se

${ }^{4}$ Genette explica que no contempla el caso de las "notas simuladas, como se encuentran con frecuencia en Borges (Tlön, Menard, Babel), a textos presentados en forma de ensayo o reseña crítica, cuyo régimen es el de las notas “ordinarias” pero en la ficción” (Genette, 2001: 280, n. 1). 
trata de una suerte de metalepsis ficcional del autor ${ }^{5}$, que se diferencia sutilmente de la autoficción en la tematización de sus componentes, pues en esta el autor se estiliza en narrador (el narrador es una máscara ficcional del autor, como ocurre en algunos relatos de Jorge Luis Borges: "Tlön, Uqbar, Orbis Tertius", "El Zahir", "El otro"...) y, en aquella, el autor en instancia textual (el autor-persona se estiliza en autorinstancia); un procedimiento que suele utilizar Macedonio Fernández. Así lo usó en No todo es vigilia la de los ojos abiertos, una de las primeras obras del autor, donde desarrolla su belarte de forma menos evidente que, por ejemplo, en Museo de la novela de la Eterna (Primera novela buena).

No todo es vigilia la de los ojos abiertos dificilmente puede catalogarse como un texto ficcional, pues se compone de reflexiones sobre metafísica, desarrolladas unas veces como textos filosóficos, y otras, como ensayos. La mayor parte de las notas a pie de página de esta obra son de carácter explicativo o complementario (ambas habituales, como ya se ha comentado, en los textos discursivos); amplían o matizan la información del enunciado de forma más o menos subjetiva, y en ocasiones, Macedonio Fernández esboza en ellas su teoría estética, coherente con la metafísica para quien la verdad, la vida y el arte son lo mismo:

No es cosa de llorar por esto. En tiempos de Calderón, y creo que por la publicación de sus dudas y espantos metafísicos que hacían Descartes y Berkeley (pura matemática y fisiquismo como en Leibniz y Spinoza); falsete de Pascal temblando entre dos infinitos — de materia nada más—; susto astronómico de las vastedades y celeridades (que se anulan recíprocamente: ¿y el susto?; no se sabe qué hacer con él) el falsete de arte y conducta era: llorar que la vida era sueño (la mejor y más substancial categoría que puede calificar al Ser [...]; inmenso capítulo del Falsete en Arte (aparentar cantar un sentimiento no efectivo). Frente a ese falsete o mal gusto: el arte torrencial; la tortura inacabable del desengaño de Sancho, el destino de Margarita y su hermano soldado, y de Mignon; la mansedumbre, ternuras y aspiración de Quijote; la triste docilidad de Otelo a desquiciar su ventura [...] (Fernández, 2001: 244, 245, nº.1).

Evidentemente, este tipo de notas preservan el carácter paratextual que se les atribuye por el lugar que ocupan, pese a su naturaleza indisolublemente discursiva (por el diálogo que mantienen con el texto que glosan); sin embargo, la bifurcación que se genera con la nota en No todo es vigilia la de los ojos abiertos desempeña funciones distintas a las mencionadas ya en la tercera parte (de las cuatro que la componen), cuando se introduce una nota preliminar de carácter seudoeditorial, en la cual se reflexiona sobre algunos temas metabelartísticos: la autoría y el proceso de creación de la obra:

Nos da Macedonio Fernández, a nuestro pedido, un esquema apresurado de su posición en metafísica. No le satisface y quisiera le acordásemos prórroga hasta el número próximo. Le decretamos la publicación ya, como espera; es virtud de lectores esperar leyendo. Cada colaboración de M.F. viene con una nota previa que pide publiquemos como nuestra, por lo que hemos resuelto declararnos autores solo de la colaboración entera, aunque vale menos que la nota (Proa, nº. 2, 1924) (Fernández, 2001: 193).

Al introducir una nota con un destinador ficticio en un texto cuyo horizonte de expectativas es el de un texto no ficcional durante las dos primeras partes, Macedonio Fernández experimenta el belarte como forma de trasgresión de los textos-tipo y desarrolla un proceso de ficcionalización (en un parapasaje) que se refuerza en sucesivas notas, donde adopta la identidad de autor-instancia textual anteriormente referida; unas veces, con la forma paratextual esperada:

Publico un borrador, que es lo que casi todos hicieron sin confesarlo, añadiéndole orden (solo en la numeración de capítulos) y solemnidad; yo solo le añado un Pájaro y un Viajero; mi borrador tiene dos aves, o mejor dicho, reconozcámoslo, un Ave y una pobre imitación, pero de cualquier manera, dos ingenuos del cambiar de lugar. Así mis aciertos no se paran donde están sus razones, en este libro; a veces el acierto se encuentra antes y las razones muy lejos: viajeras razones (Fernández, 2001: 284, nº. 1).

\footnotetext{
${ }^{5}$ Genette define la metalepsis de la siguiente manera: "[...] considero razonable destinar de ahora en adelante el término metalepsis a una manipulación [...] de esa peculiar razón causal que une, en alguna de esas direcciones al autor con su obra, o de modo más general al productor de una representación con la propia representación" (Genette, 2004: 15).
} 
Otras, con una exploración formal del propio paratexto, al desarrollar dos niveles de notas a pie de página (la nota que glosa la nota) ${ }^{6}$ :

[...] solo el amor iguala o es igualdad que merezca nombrarse; pero aquí no era del afecto lo amargo que había: eran amargos de mate, la dulzura argentina de Sud-sudamérica, con que endulzamos tanto Schopenhauer y yo:* ¡Ah, Schopenhauer $[\ldots]$ !

\begin{abstract}
*Si nos hemos encontrado, lector, desde el principio, ya estamos en confianza como para que no hagáis caso de paréntesis confundidos; son erratas que pueden acertar y las sitúo al azar, por si aclaran cuando en lo oscuro se hace aún más oscuro. Intrincadísimo lector: aquí pueden erratas más que autores. Y te tomo por ejemplo, lector: errata feliz tuya fue acertar conmigo en momento en que me separaba, con Domínguez, de Hobbes, porque aunque yo no lograra la Solución, nadie te habló tan hondo como aquí, porque solo yo sé que hay que explicar el Misterio a la Pasión y no a la Geometría, fácil de engañar: yo no te instruiré con posiciones, fuerzas, figuras, extensiones, sino con aquietamiento en el Ser y aspiración sin límites en la Pasión ${ }^{\circ}$ ¿QQué me has dicho, lector?... Creí oírte... (Fernández, 2001: 315,316, nº. 1).
\end{abstract}

El autor como instancia textual se manifiesta en ambas notas a pie de página: en la primera esboza que la escritura es una tentativa del ideal de escritura, y por ello, es siempre un proceso inacabado ("Publico un borrador, que es lo que casi todos hicieron sin confesarlo"), y en la segunda, plantea algunas ideas afines a las de la anterior nota (la escritura como proceso inacabado, incompleto y a veces defectuoso - "son erratas que pueden acertar y las sitúo al azar, por si aclaran cuando en lo oscuro se hace aún más oscuro"-) e introduce uno de los temas más característicos de los textos de Macedonio Fernández, habitualmente situado en las orillas del texto que conforman las notas a pie de página: el diálogo explícito con el lector. Es evidente que cualquier texto literario se dirige a un lector; un elemento imprescindible en la comunicación, sobre el que han teorizado varios autores (por ejemplo, Wolfgang Iser sobre el lector implícito y Umberto Eco sobre el lector modelo), tácitamente asumido en el concepto de obra. Sin embargo, Macedonio Fernández asume que hay un lector y le obliga a introducirse en sus textos al mencionarlo explícitamente:

El carácter dialógico de un texto es la piedra de toque de su literaturidad. Continuamente, Macedonio introduce al lector en sus textos, se dirige a él, piensa en él, y lo hace partícipe de su escritura. No espera que el lector se aproxime a sus textos, él mismo va a su encuentro como queriendo forzarlo a compartir su escritura.

Macedonio sobrepasa de lo que definimos como dialógico, pues más que el encuentro del lector con el texto, propone recurrentemente la introducción del lector en el texto, en un juego de inacabables e indefinidos (Isaacson, 1981: 113, 114).

Con este recurso, que en No todo es vigilia la de los ojos abiertos se utiliza únicamente en las notas a pie de página, Macedonio Fernández transforma al lector real en lector-instancia textual. De este modo, desarrolla de nuevo una metalepsis ficcional que desestabiliza la condición aficcional del texto de las dos primeras partes. Si bien la obra se desarrolla con pasajes filosóficos y ensayísticos, la aparición de notas ficcionales, enunciadas por un seudoeditor o por un seudoautor - Macedonio Fernández estilizado en autor-instancia textual-, plantea un cambio del estatus ficcional del texto por el diálogo que establecen las notas a pie de página con él.

En obras posteriores a No todo es vigilia la de los ojos abiertos, las notas ya no cumplen esta función porque el proceso de estilización se produce con las sutiles metalepsis ficcionales del autor y del lector en el propio texto. Tanto en Papeles de Recienvenido y Continuación de la Nada como en Museo de la Novela de la Eterna (Primera novela buena) el autor-instancia textual apela directamente al lector-instancia en el propio texto, consciente de que las interrupciones y los paréntesis son parte esencial de su belarte, porque contribuyen a la disolución del asunto. Así, en Papeles de Recienvenido y Continuación de la Nada, el

\footnotetext{
${ }^{6}$ La primera tentativa de dos niveles de notas se desarrolla en No todo es vigilia la de los ojos abiertos con temas afines a los del discurso del texto; esta nota supone, por tanto, una exploración únicamente formal:

¿Qué es en esencia esta periodicidad? El quantum de tiempo* que transcurre entre dos hechos es enunciación que carece de sentido: lo único que percíbese es la simultaneidad de dos hechos y la frecuencia de esa simultaneidad [...].

*No solo el quantum de tiempo o de espacio carece de sentido, sino el "quantum de materia" que tanto intriga a los físicos (Fernández, 2001: 268, 269, $\left.\mathrm{n}^{\mathrm{o}} .4\right)$
} 
narrador-autor-instancia textual se manifiesta habitualmente en el propio texto y, en ocasiones, apela al lector-instancia textual para explicitar su poética narrativa: el asunto de la nada, que es anti-asunto concretado en la digresión continua: "Un instante, querido lector: por ahora no escribo nada. Estoy callado para meditar acerca de un telegrama que leo en La Prensa [...]” (Fernández, 2010: 41).

De este modo, la nota a pie de página se evidencia como un espacio para entablar un diálogo con el lector, donde se consolida el que mantiene en el texto; en ningún momento desestabiliza el estatus ficcional de la obra, precisamente porque los procedimientos metalépticos se desarrollan como parte de ella en el texto no orillado.

En Continuación de la Nada hay una nota que remite al proceso de lectura de un texto y a la función inherente a estos paratextos, la de irrupción (y descanso) del texto: "Noto que aquí el lector clama por un descanso. La Nada lo ahoga" (Fernández, 2010: 178) ${ }^{7}$. Este último rasgo también se evidencia en una nota a pie de página en que se conjuga la experimentación formal de los dos niveles de notas con el contenido belartístico:

La epistolar biografía la hago conocer a mi lector actual para que se diga de mí, tenga o no otros méritos: "Era hombre de hechos - que biográficamente son actos- como el de recibir cartas amenísimas, cartas con una total y amenísima "biografía por correo", espontáneamente, de persona que sin trato durante diez años simuló haberse olvidado de olvidarlo, o disimuló haberse olvidado de olvidarlo"*

*O: "Disimuló de haberse olvidado de olvidarlo, o simuló haberse acordado de olvidarlo". Arrégleselas, lector; entienda, pierda un kilo aquí, no le hará mal; no le pese, que, siguiendo, pronto pesaremos lo mismo (Fernández, 2010: 179) ${ }^{8}$.

La función metadiscursiva de las notas a pie de página que Macedonio Fernández tantea en No todo es vigilia la de los ojos abiertos, en Papeles de Recienvenido y en Continuación de la Nada se convierte en una pauta del belarte perfeccionado en Museo de la novela de la Eterna, obra publicada póstumamente, donde Macedonio Fernández explora la textualidad de los paratextos y la completa adecuación de su arte literario a estas formas:

Llamar su texto un museo es un chiste, cierto, pero un chiste serio, una broma dirigida al lector seguido que quisiera leer una novela como si hiciera una visita guiada. La metáfora del museo, que engloba el texto por su posición liminar a la entrada al mundo novelístico, advertencia de abandonar toda esperanza de poder escaparse del juego textual para hallar un sitio metadiscursivo donde el lector recobrara su control hermenéutico, es, paradójicamente, una clave imprescindible para penetrar el laberinto macedoniano (Johnson, 2003: 86).

Museo de la novela de la Eterna también puede concebirse como un homenaje al personaje inspirado en Elena de Obieta, la mujer de Macedonio Fernández, que falleció en 1920 y vive en su obra como un aforismo literario recurrente, similar al de Getrude Stein: Elena de Obieta es Elena Bellamuerte ${ }^{9}$ es la Eterna es Elena de Obieta... La obra se divide esencialmente en dos partes: la primera se compone de más de cincuenta prólogos — a lo nunca visto, a la eternidad, al autor, al lector, a los personajes, "Guía a los Prólogos (prólogo indicador)" (Fernández, 2012: 76), etc.—, y la segunda, de veinte capítulos aunados con el título: "Despierta, comienza el tiempo de la novela. Muévese". Los capítulos también se componen fragmentariamente, pues se dividen en varios epígrafes — por ejemplo, "Un día de los habitantes de "La Novela"” (Fernández, 2012: 152), "Una de las cinco "páginas sueltas de la novela"” (Fernández, 2012: 176), "Modelo de página suelta de la novela" (Fernández, 2012: 217)_, cuyo desarrollo evidencia que la aparente unidad se debe solo a los títulos rigurosamente numerados, al tono humorístico y al tema general del belarte narrativo, pero no al argumento, del que, coherentemente, carece.

\footnotetext{
${ }^{7}$ En el capítulo "Biografía de mi retrato en Papeles de Recienvenido (Pose $n^{0} .3$ )".

${ }^{8}$ Esta nota se halla en "Biografía por correo (Pose $\left.n^{\circ} .4\right)$ "; en la nota que glosa la primera se evidencia el carácter bifurcador de estos paratextos (en el comienzo disyuntivo: "O").

9 "Elena Bellamuerte" es el título del poema que Macedonio Fernández dedica a Elena de Obieta y que comienza así: "No eres, Muerte, quien por misterio / pueda mi mente hacer pálida / cual eres ¡si he visto / posar en ti sin sombra el mirar de una niña! / De aquella que te llamó a su partida / y partiendo sin ti, contigo me dejó [...]" (Fernández, 2004: 109).
} 
Macedonio Fernández también usa en Museo de la novela de la Eterna notas seudoeditoriales ${ }^{10}$ y seudoautorales ${ }^{11}$, humorísticas como algunas de obras anteriores, que no desestabilizan el estatus ficcional del texto. No obstante, exploran significativamente la función metadiscursiva, pues el autor y el lector como instancias textuales son motivos habituales del no-asunto de Museo de la novela de la Eterna.

Asimismo, se reconocen funciones de las notas a pie de página distintas a las tanteadas en obras anteriores, como la provocación explícita del lector. En el prólogo "A los lectores que padecerán si ignorasen lo que la novela cuenta", cuyo título ya denota cierto desafío a la instancia textual lectora, se introduce una nota que explicita la actitud desafiante del autor cuando glosa la siguiente parte del texto: "Si has de leer del todo, como pronóstico, no andes probando de mi novela aquí y allá para ver: si ya está, si le falta azúcar o fuego; e hicieras mejor cual mi dueño de casa que, "solo para probar", como dice mansamente a la cocinera, se ata servilleta y se da cuchillo y tenedor" (Fernández, 2012: 30, 31):

"Postre muy probado es mejor pero no llega a comedor." "Quedarse en la cocina es, en la mesa, convidado y ausencia." "Comensal invisible pero aprovechado."

Refranes de mi ingenio para molestar al lector salteado que ande diciendo que pudo leer a medias mi novela, dejar de leer la mitad salteada. Lo que nadie resistirá a hacer con mi muy quedada y precedida novela. Lo tengo tan dominado a mi lector salteado, que será el único de su género que habrá leído lo salteado (Fernández, 2012: 31, nº 1).

Otros procedimientos que se articulan con las notas a pie de página en Museo de la novela de la Eterna tienen que ver con la función fáctica del lector; así, se muestra el diálogo de este con autores mencionados por el autor, la metáfora literal que muchos escritores han concretado textualmente —Platón con Sócrates, Petrarca con Agustín de Hipona...- - un discurso paratextual no escrito, con que se denota el dialogismo de la lectura: "El lector cuchichea con Hogdson y el autor percibe que ambos anotan acotaciones marginales"12 (Fernández, 2012: 61, nº. 1).

Quizá una de las funciones más significativas y diferenciadas de las notas a pie de página de Museo de la novela de la Eterna es conformar un discurso unificado sobre las acciones metadiscursivas; concretamente, las relativas a las reacciones del lector, que se establece en ambas partes de la obra. La nota que comienza el discurso diseminado y unificador está en el prólogo "Carta genial que yo quisiera que uno de mis personajes, el Presidente, escribiera a Ricardo Nardal", que glosa el sintagma "Carta genial" del título y alude a las expectativas que suscita en los lectores y a la congregación de estos que determina: "Agolpamiento de lectores a la expectativa" (Fernández, 2012: 118, $\mathrm{n}^{\circ}$. 1). La multitud congregada en el prólogo comienza a disolverse en "Imprecación para el lector seguido", donde el escarnio al tipo de lector no deseado para el belarte macedoniano comienza a producir bajas lectoras; de este modo, la severa imprecación —"iQué te costaría callarte, hombre! ¿No te da pena ajar el sereno y doloroso talante de la Eterna? ¿No te conquista el destino cruel y la mansedumbre de la tierna Dulce-Persona? [...]" (Fernández, 2012: 131, la cursiva es del autor) - determina "68 bajas de lectores" (Fernández, 2012: 131, no. 1). El discurso diseminado en las notas a pie de página sobre el no-asunto metalectoral continúa en "Capítulo IX (En el tiempo entre dos expulsiones de Federico que se acerca veinte veces cada día a "La Novela" desierta)", donde se anuncian más bajas de lectores por una estilística descuidada, que quizá se debe al agotamiento reconocido del autor:

${ }^{10}$ A veces interviene el "editor", como en la nota final del capítulo "1. "Nota de prosprólogo; y 2. observaciones de ante-libro": "Observación del Editor: se me permitirá el aserto respetuoso de que, en efecto, el gran novelista que estoy aquí editando y cuyas dotes de ingenio y fácil extensión de párrafos todo el público conoce desde lejos (con nuestra propaganda se acercará más) ha necesitado (no hablemos de dineros) a veces, cuando ya no podía más con su literatura, enviamos entre sus manuscritos algunas páginas en blanco, foliadas seguidamente, de algún relato trunco, y hemos comprendido que nos tocaba hacer algo fuera de contrato" (Fernández, 2012: 134).

${ }^{11}$ Es especialmente significativa la nota a pie de página de "Capítulo VII (La Vida quiere entrarse a la novela.)", que glosa una intervención del autor en el propio texto, y por ello, este aparece como un personaje más: “-El autor*: ¡Qué escalofrío! Quisiera darles todas la palabras que piden y pidieran $^{\circ}$. ¡Cuánta pena! ¿Pero han podido alguna vez las palabras dar lo que ellos esperan? ¡Por suerte, a menos que no sea la Eterna quien me implore tener vida [...]" (Fernández, 2012: 188). La nota que glosa "El autor" no la escribe el autor-instancia textual, quien está (metalépticamente) en el discurso, sino una inquietante instancia narrativa suprautoral: "El autor parece asustarse y cree tener el ser de personaje, atrapado por su propio invento. ¿Se recobrará alguna vez? ¡Si quedara para siempre! Es la décima vez que le acontece: por dos años todos los días ha tenido poco o mucho pensamiento de estos personajes, y a veces ha conocido el sudor y suspensión de ser él nada más que personaje. ¿Tiene más realidad que ellos? ¿Qué es tener realidad?” (Fernández, 2012: 188, nº. 2).

${ }^{12}$ El texto que glosa esta nota a pie de página menciona al autor con quien cuchichea el lector: "El autor, partiendo de esta magna lección de Hogdson [la concepción del automatismo psicológico], no se intimidó de llevarla a su más extrema sistematización [...]” (Fernández, 2012: 61). 
Si este capítulo de la Conquista del autor lo hubiera realizado lozana y graciosamente, hubiera falseado la psicología de esa Acción ${ }^{\circ}$. Por lo demás, a mi incrédulo y listo lector lo satisfaré confesando que el capítulo es simplemente la obra de un autor en agotamiento, que no da más.

Pese a cuya confesión no puedo evitar verificar 63 bajas de lectores exigentes de una estilística impecable (Fernández, 2012: 207, no. 2).

La nota al pie que concluye el discurso paratextual iniciado en los prólogos glosa el final del capítulo XIII, donde el Presidente — uno de los álter ego de Macedonio - y Dulce-Persona viajan en coche y reflexionan sobre el tiempo y la vejez:

- [...] La vejez es simplemente no los años sino toda relación de excesiva carga de la vida con respecto a la reactividad personal psicológica.- Y también le hará ver el Presidente el ridículo de su vida: que desde hace treinta años estudia al mismo tiempo biología, es decir, cómo no morir, y metafísica, es decir, cómo nadie muere.

Entonces Dulce-Persona le dirá al Presidente, como un murmullo:

— ¿Por qué no podríamos seguir así, en este Cochecito, toda la vida, sin pasar el tiempo, sin apreciarnos menos, todos juntos, en "La Novela"?

— ¿Por qué no? (Fernández, 2012: 229).

La inmortalidad de los personajes en Museo de la novela de la Eterna se debe a que la obra es "La Novela"; es decir, una novela belartística, sin asunto, que permite plasmar toda la vida porque en ella no pasa el tiempo (precisamente, por la ausencia de asunto). Tras el último pasaje citado, el capítulo concluye con un personaje apenas presente en la obra: el Viajero, que ha agotado el viaje:

$\mathrm{Y}$ en este mismo instante el Viajero (Viajero pero no de museos es el nuestro; mira lo que vive, no el Pasado), se acerca a la playa del Plata, frente a los portones de la estancia.

— ¿Y tú podrías ser feliz, Viajero, ahora agotada tu busca?

—Quizá, porque es busca inventada, no impuesta (Fernández, 2012: 229).

El Viajero se menciona puntualmente en los primeros prólogos, donde se caracteriza como un personaje vinculado al lector:

Así, pues, a medida que escribo, indago y espero sucesos, como el lector. Y cuando pienso en el lector salteado, advierto que debo imaginar qué corresponde darle a sentir al Viajero después de lo que acababa de ocurrir, para deducir qué es lo probable que dijo y no sé yo. lo que haya dicho será lo que yo os diga. No es improbable que él haya articulado: "Soy Viajero en Novela, en un relato en marcha: no debo, pues, detenerme y en esta escena ya demasiado estuve. Que el lector me vea alcanzando el tren o zarpando en todo momento [...]" (Fernández, 2012: 32, 33).

A él le encomiendo salvar la fantasía aquí, si todo falla; al Viajero que en la misma vida quizá no existió nunca, pues no creo en los Viajeros; los dos sentimientos que definen al Viajero de calidad son la facultad y deseo de olvidar y el deseo de ser olvidado [...]. La muerte que hay en los dos olvidos es la que nos ha llevado al error de creer en la muerte personal. Pero esta creencia es debilísima, por eso hacemos mucho más por no ser olvidados que por no morir.

- Y entonces, ¿por dónde erra y anda nuestro Viajero?

- Mi Viajero vive allí enfrente. Y no sale de su casa sino a la hora de fin de capítulo en la novela.

Funciona únicamente como extinguidor de la alucinación que llegue a amenazar de realismo al relato (Fernández, 2012: 45).

Asimismo, el Viajero es el personaje inevitablemente ausente ${ }^{13}$ en el belarte de Macedonio Fernández porque en este nunca se desarrolla un relato en marcha, ni la narratividad temporal y no reflexiva. De modo que,

${ }^{13}$ En el prólogo "Dos personajes desechados” se caracteriza así al Viajero: "Quisiéramos hablar de cada tipo de personajes pero solo explicaré a uno, a ese personaje faltador, porque toma en serio su papel de Viajero, que está siempre en este viaje inextinguible [...]” (Fernández, 2012: 88, 89). 
cuando el Viajero aparece al final del capítulo XIII, cumple la función de anular el realismo (el asunto) del texto, pues se anuncia que su busca se ha agotado. En la nota al pie que glosa este final, se refuerza la analogía del Viajero-lector: "De aquí en adelante el autor sigue solo. Los últimos lectores se dan de baja al autor. Y, naturalmente, retíranse a escribir" (Fernández, 2012: 229, $\mathrm{n}^{\circ}$. 1). Quizá no sea casual que esta sea la última nota de Museo de la novela de la Eterna, pues ya se ha dicho que es un espacio de diálogo con el lector y los que quedaban se han retirado "a escribir". La cursiva del final de la última nota de la novela denota que el lector también es un escritor - ya se leía entre líneas, en la que se mencionan los cuchicheos con Hogdson y las acotaciones marginales, que ambos escriben - , y quizá, por ello, el autor ha mantenido el continuo pugilato dialéctico con él. Para entender el tipo de escritura que realiza el lector, cabe acudir de nuevo aquí al parapasaje metabelartístico de No todo es vigilia la de los ojos abiertos, donde se completa el sentido del Viajero al intuir las asociaciones del Viajero-lector y del Pájaro-autor: "Publico un borrador, que es lo que casi todos hicieron sin confesarlo [...]; yo solo le añado un Pájaro y un Viajero; mi borrador tiene dos aves, o mejor dicho, reconozcámoslo, un Ave y una pobre imitación, pero de cualquier manera, dos ingenuos del cambiar de lugar" (Fernández, 2001: 284, $\mathrm{n}^{\circ}$. 1). El Viajero es una imitación pobre del Pájaro en una hermenéutica macedoniana, quizá porque este escribe (belartísticamente) y aquel escribe (de forma realista, con asunto y temporalidad); un concepto que se emparenta con las teorías de la Estética de la Recepción más extremas, como la del lector informado (de Stanley Fish), en quien recae completar el sentido del texto literario - y por ello, en cierto modo, lo escribe-.

La relación análoga y complementaria de autor y lector se muestra, asimismo, en una de las notas en que Macedonio Fernández experimenta con los aspectos formales y funcionales de estos paratextos. Se trata del prólogo "El hombre que fingía vivir (Único personaje que necesita explicación . Y la tiene doble*: le faltó la existencia pero abundó de aclaraciones)" (Fernández, 2012: 73), que se compone únicamente del título, el subtítulo (desarrollado entre paréntesis) y la extensa nota a pie de página que glosa al sintagma: "Y la tiene doble". La nota abarca tres páginas y es el único texto del que se compone el prólogo, de modo que es lícito cuestionar su función paratextual e interpretarlo como un seudoparatexto. El texto, formalmente paratextualizado, concluye dirigiéndose al lector, una vez más: "El lector comprobará que si del desempeño de todos los personajes estamos contentos el lector y yo y no sabemos cómo agradecer que nos hayan acompañado hasta el Fin, como nos hemos acompañado el lector y yo [...]" (Fernández, 2012: 75, nº 1). Parece paradójica la afirmación de que el lector y el autor se acompañan hasta el Fin, sobre todo, si se confronta con aquella en que se anuncia que el lector abandona al autor cuando aún queda novela escrita, para ponerse a escribir (en el capítulo XIII); sin embargo, probablemente ambas afirmaciones son coherentes a la luz de la transformación del lector-instancia textual en lector-autor, que refuerza el sentido de la escritura como ejercicio solitario, en que el autor termina con la única compañía del álter ego que conforma su lector modelo.

En cualquier caso, el motivo recurrente del diálogo de ambas instancias textuales en algunas notas metadiscursivas de Museo de la novela de la Eterna conforma un discurso con el cual se evidencia que estos paratextos desempeñan una función cohesiva de la obra fragmentaria; un ejemplo más de las diversas funciones con que Macedonio Fernández usa las notas a pie de página, las cuales posibilitan el desarrollo de su belarte, fundamentado esencialmente en la ausencia de asunto ${ }^{14}$, el fragmentarismo y la teoría y la creación conjugadas en los escritos:

Quizá lo más destacable de ese período sean las constantes interrelaciones entre la actitud creadora y la teorización ${ }^{\circ}$. Este aspecto, ya esbozado en No todo es vigilia a través de notas a pie de página, digresiones o paréntesis, que interrumpían - a veces humorísticamente- el desarrollo del texto, se hace ahora más evidente como recurso programático. Al conocerse la última versión de Museo... se advertirá que ese procedimiento intertextual es uno de los rasgos distintivos en la ruptura novelística de Macedonio (Salvador, 2003: 127).

Efectivamente, las notas acaban siendo un recurso programático de la obra macedoniana; suponen la digresión extrema y ello conforma el discurso ideal del autor. El propio Macedonio Fernández lo razona en una nota a pie de página de "Cirugía psíquica de la extirpación" — un relato en que esboza someramente el

\footnotetext{
14 "La trama novelesca queda minimizada en favor de unos paratextos que postulan y bifurcan lucubraciones metaliterarias en torno a distinto tipo de personajes y lectores" (González, 2003: 43).
} 
argumento de un hombre al que le extirpan el recuerdo del asesinato de su familia—, en la cual se explicita la importancia de las notas en su belarte:

Mi sistema de interponer notas al pie de página, de digresiones y paréntesis, es una aplicación concienzuda de la teoría que tengo de que el cuento (como la música) escuchado con desatención se graba más [...]. Hago lo mismo con estas digresiones, desviaciones, notas marginales, paréntesis a los paréntesis y alguna incoherencia quizá, pero la continuidad de la narrativa la salvo con el uso sistemático de frecuentes $y$, y confieso que lo único que me sería penoso que no me aplaudan es este sistema que propongo y cumplo acá. Es imposible tomar en serio un cuento, me parece infantil el género, pero no por eso resulta que este sea burla del cuento, porque mi sistema digresivo ya lo dejo defendido y la continuidad y apretado narrar me preocupo hacerlo lucir mediante las $y$.

Las y y los ya hacen narrativa a cualquier sucesión de palabras, todo lo hilvanan y "precipitan” (Fernández, 2004: $\left.88, n^{\circ} .6\right)$.

Así, Macedonio Fernández utiliza el carácter digresivo de la nota al pie para afianzar la ausencia de asunto en los textos y el carácter orillado; así conjuga la creación y la teoría, tratándolas de forma separada, cada una en uno de los planos textuales que se configuran con estos paratextos, como en "Cirugía psíquica de la extirpación", cuyo somero asunto se desarrolla en el texto y la teoría belartística, en las notas. Por último, cabe destacar que el carácter orillado también sirve para desarrollar diversos procedimientos textuales inexplorados hasta entonces: conformar la cohesión de un texto fragmentario y sin asunto, cambiar el estatus ficcional de sus textos y generar metalepsis ficcionales con el autor y el lector; un procedimiento vital de Macedonio Fernández, el autor-Viajero de sus propios textos.

\section{Referencias bibliográficas}

Attala, Daniel (2014). Macedonio Fernández “Précurseur” de Borges. Rennes: Presses Universitaires de Rennes.

Becco, Horacio Jorge (1973), “Contribución a la bibliografía de Macedonio Fernández”, en Noé Jitrik. La novela futura de Macedonio Fernández. Caracas: Ediciones de la Biblioteca (Universidad Central de Venezuela), págs. 125-144.

Borinski, Alicia (1972), "Macedonio: su proyecto novelístico", Hispamérica. Revista de Literatura, año 1, nº 1, págs. 31-43.

Bustos Fernández, María (1996), "La narrativa de vanguardia en Argentina”, en Vanguardia y renovación en la narrativa latinoamericana. Madrid: Editorial Pliegos (Pliegos de ensayo), págs. 23-66.

Camblong, Ana (2006). Ensayos macedonianos. Buenos Aires: Ediciones Corregidor.

-----------, ----- (2007), "Pensar-escribiendo a la criolla", en Daniel Attala (ed.). Impensador mucho. Ensayos sobre Macedonio Fernández. Buenos Aires: Ediciones Corregidor, págs. 147-177.

Cívico-Lyons, Inmaculada (2017), "El humor de Macedonio Fernández según la teoría del humor basada en esquemas semánticos”, Hispania, vol. 100, n. 3, págs. 450-460.

Díaz, Lidia (1990), "La estética de Macedonio Fernández y la vanguardia argentina", Revista Iberoamericana, Abriljunio, vol. LVI, no. 151, págs. 197-511.

Echavarren, Roberto (1979), "La estética de Macedonio Fernández”, Revista Iberoamericana, Enero-junio, vol. XLV, $n^{\circ}$. 106-107, págs. 93-100.

Fernández, Macedonio (1997). Teorías. Obras completas, volumen III. Buenos Aires: Ediciones Corregidor.

Aires: Ediciones Corregidor.

poesía y metafísica. Barcelona: Tusquets, págs. 77-89.
- -orregidor. VI. Buenos Aires: Ediciones Corregidor.

Fernández Moreno, César (1960). Introducción a Macedonio Fernández. Buenos Aires: Editorial Talía.

García, Germán (2000). Macedonio Fernández. La escritura en objeto. Buenos Aires: Adriana Hidalgo editora.

Genette, Gérard (2001). Umbrales. Trad. de Susana Lage. Argentina: Siglo XXI.

--------, ------- (2004). Metalepsis. De la figura a la ficción Trad. de Luciano Padilla López. Buenos Aires: Fondo de Cultura Económica.

Gómez de la Serna, Ramón (2010), "Retrato de Macedonio Fernández", en Macedonio Fernández. Papeles de Recienvenido y Continuación de la Nada. Buenos Aires: Ediciones Corregidor, págs. 5-31.

González, Horacio (1995). El filósofo cesante. Gracia y desdicha en Macedonio Fernández. Buenos Aires: Atuel.

González Álvarez, José Manuel (2009). En los "bordes fluidos”: formas híbridas y autoficción en la escritura de Ricardo Piglia. Berlín: Peter Lang. 
González Martínez, Henry (1998), “El minicuento en la narrativa de Macedonio Fernández”, THESAURUS, tomo LIII, $\mathrm{n}^{\mathrm{o}} .3$, Centro Virtual Cervantes, págs. 605-616.

Isaacson, José (1981). Macedonio Fernández, sus ideas políticas y estéticas. Buenos Aires: Editorial de Belgrano.

Jitrik, Noé (1973). La novela futura de Macedonio Fernández. Caracas: Ediciones de la Biblioteca (Universidad Central de Venezuela).

Johnson, Warren (2003), “Toca, por favor: el museo textual de Macedonio Fernández”, Hispanofila. Sep. nº 139, págs. 83-96.

Lindstrom, Naomi (1985), "Macedonio Fernández y su reinvención del discurso metafísico", Revista de Crítica Literaria Latinoamericana, Enero, 1, nº. 21/22, págs. 151-164.

Luque García, Ander (2017). Diálogo con el lector y “promesa de obra” como obra literaria. La inversión emisorreceptor a partir de la novelística de Macedonio Fernández. Tesis doctoral. Barcelona: UBA.

Mattalía, Sonia (1992), "Macedonio Fernández/Jorge Luis Borges: la superstición de las genealogías", Cuadernos Hispanoamericanos, $\mathrm{n}^{\circ}$. 505-507, págs. 497-506.

Niemeyer, Katharina (1994), "Las novelas de Macedonio Fernández”, en Hans-Otto Dill, Carola Gründler, Inke Gunia y Klaus Meyer-Minnemann. Apropiaciones de realidad en la novela hispanoamericana de los siglos XIX y XX. Madrid: Iberoamericana-Vervuet, págs. 242-256

------- (2004). Subway de los sueños, alucinamiento libro abierto. La novela vanguardista hispanoamericana. Madrid: Iberoamericana-Vervuet.

Orquera, Fabiola (1994), "Procedimientos constructivos en el Museo de la novela de la Eterna", Revista Chilena de Literatura, nº 45 , págs.53-64.

Piglia, Ricardo (ed.) (2000). Diccionario de la novela de Macedonio Fernández. Buenos Aires: Fondo de Cultura Económica.

Prieto, Julio (2010). De la sombrología. Seis comienzos en busca de Macedonio Fernández. Madrid: IberoamericanaVervuet.

Salvador, Nélida (2003). Macedonio Fernández. Creador de lo insólito. Buenos Aires: Ediciones Corregidor.

Sosnowsky, Saúl (1987), "Sobre la crítica de la literatura hispanoamericana: balance y perspectivas", Cuadernos Hispanoamericanos, $\mathrm{n}^{\circ} .443$, págs. 143-159. 